\title{
Determinants of Modern Contraceptive Utilization among Women of Reproductive Age in Cambodia
}

\author{
Davy Hut ${ }^{1}$, Natnapa Heebkaew Patchasuwan ${ }^{2}$, Kittipong Sornlorm², Wongsa Laohasiriwong ${ }^{3}$ \\ ${ }^{1}$ Master of Public Health Program (International) Faculty of Public Health, KhonKaen University, Thailand, \\ ${ }^{2}$ Lecturer,Faculty of Public Health, KhonKaen University, Thailand, ${ }^{3}$ Associate Professor, Faculty of Public \\ Health, KhonKaen University, Thailand
}

\begin{abstract}
Background: Contraceptive uptake remains a public health concern in Cambodia. Therefore, the aim of this study was to determine the modern contraceptive use pattern and itsassociated factors among women of reproductive age in Cambodia.

Method: A cross-sectional study used the data from the Cambodia Demographic and Health Survey. This survey adopted a two-stage stratified random sampling process to select respondents to respond a structured questionnaire interview. The multiple logistic regression was applied to determine the association.

Results: Of the total 7,606 women, 51.04\% used modern contraceptives. Themultivariable analysis indicated the use of modern contraceptives was strongly associated with fertility preferences, ideal number of children, number of living children, husband's desire for children,age at first marriage, number of induced abortions, and marriage to a first birth interval. Health service factors including sources of family planning information, visited health facilities, inaccessibility to health service as well as sociodemographic factors such as women's age, occupation, and geographical regions also significantly associated with modern contraceptive use.
\end{abstract}

Conclusions: About half of women in Cambodia used modern contraceptives. Reproductive, health service and sociodemographic factorswere essential for modern contraceptive utilization.

Keywords: Determinants, modern contraceptives, women of reproductive age.

\section{Introduction}

Contraception has helped millions of people to control their fertility. The adoption of effective contraception can lower the burden of obstetric complications during childbirth and pregnancies, mitigate the number of abortions, prevent undesired pregnancies, and reduce infant and maternal mortality. ${ }^{1}$ Globally, an overwhelming majority of reproductive age women are using various contraceptive method, with more than one out of ten in-union or married women were not practicing any contraceptive method but wanting

\section{Corresponding Author:}

\section{Natnapa Heebkaew Patchasuwan}

Address: Lecturer, Faculty of Public Health, KhonKaen University, Thailand

e-mail: natnpa@kku.ac.th to halt and delay their childbearing. ${ }^{2}$ More than $90 \%$ of all contraceptive users, modern contraceptives were practiced by approximately $55 \%$ of married reproductive age women in almost all territories in the world in 2000 , with a marginal increase of roughly $58 \%$ in 2017.2

Contraceptive use can prevent approximately 54 million unplanned pregnancies, a million infant deaths, and 79,000 maternal mortality. ${ }^{3}$ In 2019, approximately 842 million reproductive age women used any kinds of modern method, constituting female sterilization (24\%), male condom (21\%), IUD (17\%), and pills (16\%). ${ }^{4}$ Around 225 million women in developing nations averted the contraceptive utilization despite wanting to postpone or stop their motherhood. ${ }^{1}$ There were approximately 213 million pregnant women, of which 85 million $(40 \%)$ were undesired pregnancies, with the highest proportion in the Latin America and Caribbean zones and the lowest in Africa. ${ }^{5}$ 
Extensive research has beenstudied to identify factors influencing modern contraceptive utilization. In particular, a wide of determinants including residence site $^{6}$, religion ${ }^{1}$, age ${ }^{6}$, education level ${ }^{6}$, parity $^{14}$, financial status $^{6}$,access to media ${ }^{16}$, number of living children ${ }^{12}$, age at first marriage ${ }^{6}$, age at first sexual intercourse ${ }^{6}$, and perceptions on contraceptive uses. Other possible associated factors were women's fertility preference or partners' desire for children ${ }^{13}$, employment status ${ }^{1}$,counselling about family planning by healthcare providers, and couple's discussionconcerning contraceptive utilization. ${ }^{12}$

Cambodia, one of the least developed nations in Southeast Asia, has only about 16 million population. Cambodia had an extremely lowmodern contraceptive coverage rate despite a considerable rise in contraceptive uptake from $24 \%$ in 2000 to around 51\% in 2010 among married reproductive age women. ${ }^{14}$ Cambodia still faces many significant challenges affecting contraceptive utilization among women. The findings of the 2014 Cambodia Demographic Health Survey showed that opportunities to meet women's family planning need have not been well improved and the number of nonusers remains high, which will place a burden on the economy and the welfare of the country as a whole. ${ }^{15}$ Hence, the understandings of factors influencing modern contraceptive utilization become incredibly crucial to inform policymakers to select appropriate and tailored interventions to mitigate adverse effects of reproductive health and expand the coverage of contraceptive uptake among women. Few studies have explored information regarding characteristics and related factors of modern contraceptive uptake in Cambodia. Thus, this study aimed to describe the modern contraceptive coverageand identify the association between modern contraceptive use and other factors.

\section{Materials and Method}

Study Design: This analytical cross-sectional study used the data retrieved from the 2014 CDHS. The 2014 CDHS was conducted between June $2^{\text {nd }}$ and December $12,{ }^{\text {th }} 2014$. Further details can be seen in the 2014 CDHS report. ${ }^{15}$

Dependent Variable: Theoutcome wasmodern contraceptive uptake of married or in-union women of reproductive age (15-49 years old). Modern contraceptive use was defined as married/in-union reproductive womenor her husband/partner used at least one of the contraceptive method including condoms, emergency contraception, pills, injectables, female sterilization, male sterilization, implants, and IUD coded as 1 . Those who didnot use any contraceptives (either coitus interruptus, rhythm method, or folkloric method) were coded as 0 . The responses were then created and categorized as a dichotomous variable (Yes/No).

Independent variables: A set of explanatory variables was selected for the analysis.

Statistical analysis: All analyseswereperformed by using the Stata program version 14.0. The baseline characteristics and other variables were analyzed and presented as frequency and proportions for categorical data and mean, standard deviation, median, maximum, minimum for continuous data. The data was analyzed considering complex sampling design of the CDHS data.

A simple logistic regression was used to identify the association of each independent variable with modern contraceptive uptake. The independent variables that had $p$-value $<0.25$ were processed to the multivariable analysis. The multiple logistic regression was utilized to determine the strength of the association between modern contraceptive use and other variables, adjusted all confounders, and showed adjusted OR, 95\% CI, and P-value. In the final model, the significance level was considered at $\mathrm{p}$-value less than 0.05 .

\section{Results}

Sample Characteristics: Out of 7606 women of reproductive age, $87.27 \%$ resided in rural areas, $43.62 \%$ were in Central plain, and $43 \%$ were poor. The women averageage was 32.99 years old, $56.29 \%$ of women and $47.88 \%$ of husbands attained primary education. The highest proportion $(42.38 \%)$ were self-employed in the agricultural sector. The mean age of husband was 35.88 \pm 9.02 years old.

The mean age at marriage was $19.50 \pm 3.76$ years, $34.38 \%$ got married between the age of 18 and 20 years old, $55.97 \%$ had first sexual intercourse before the age of 20 years.

Most of therespondent had two or more parities (73.41\%), 83.14\% never had induced abortions, $41 \%$ had three or more living children, $47.20 \%$ had $12-24$ months first birth interval after marriage. Majority did not want any more children(55.42\%), $64.10 \%$ of the couples desired the same number of children and $31 \%$ had not want more than 2 ideal children. 
More than half (55.77\%) heard about family planning from family and friends, $48.36 \%$ from $\mathrm{TV}$, $47.37 \%$ from billboards or posters, radio (36.33\%). A quarter $25 \%$ got the information from community councils and $21.26 \%$ from local campaign. More than half $(51.13 \%)$ of women visited health facilities during the past 12 months, $24.22 \%$ were visited by family planning staff, $24.75 \%$ experiencing inaccessibility to health services.

Only $51.04 \%(49.19 \%-52.88 \%)$ of the women of reproductive age used modern contraceptives, of which $25.08 \%$ of all respondentsused oral pills, followed by injection(13.09\%), IUD (6.37\%), and Norplant(3.13\%). Only $2.99 \%$ used condoms and $0.38 \%$ used other method.

Bivariate Analysis: The bivariate analysis indicated that potential associated factors with contraceptive use (p-value $<0.25$ ) were: women's age, women's education, women's occupation, geographical region, husband's age, husband's occupation, parity, age at first marriage, age at first sexual intercourse, number of living children, number of induced abortions, marriage to first birth interval (months), media exposure to family planning from TV or newspapers, sources of family planning information, perceived problems in accessing to healthservices, fertility preferences, husband's desire for children, and ideal number of children. These variables were employed to the multiple variable analysis using multiple logistic regression.
Multivariable Analysis: The multivariable analysis indicated that themodern contraception was significantly more likely to be used among women who wanted children after two years (adj.OR=5.35, 95\%CI $=4.09-7.00)$, despite unsure timing $(\operatorname{adj} . \mathrm{OR}=4.40,95 \% \mathrm{CI}=2.75-7.04)$, and undecided (adj. $\mathrm{OR}=2.97,95 \% \mathrm{CI}=2.32-3.82$ ); had $\leq 2$ ideal children $($ adj.OR $=2.65,95 \% \mathrm{CI}=2.09-3.37), 3$ ideal children (adj.OR=1.91, 95\% $\mathrm{CI}=1.55-2.35)$; and 4 ideal children (adj.OR=1.48, 95\% CI=1.19-1.83); had two living children (adj. $\mathrm{OR}=2.22,95 \% \mathrm{CI}=1.82-2.70)$, and more living children (adj. $\mathrm{OR}=2.55,95 \% \mathrm{CI}=1.96-3.31$ ); husband desired for fewer children (adj.OR=1.71, 95\% CI $=1.23-2.38$ ), more children $(\operatorname{adj} . \mathrm{OR}=1.49$, $95 \% \mathrm{CI}=1.18-1.88)$, and the same number as his wife (adj.OR $=1.45,95 \% \mathrm{CI}=1.18-1.79$ ); first birth interval less than 12 months after marriage (adj.OR $=1.64$, $95 \% \mathrm{CI}=1.37-1.96)$, one year to two years $(\operatorname{adj} . \mathrm{OR}=1.39$, $95 \% \mathrm{CI}=1.20-1.60$ respectively.Health education especially received family planning information from community councils (adj. OR $=1.24,95 \% \mathrm{CI}=1.06-1.45)$ as well as visiting health facilities (adj. $\mathrm{OR}=1.23,95 \%$ $\mathrm{CI}=1.09-1.38)$ and had accessibility to health services were also associated factors. Other significant factors were socio-demographic characteristicsincluding women aged $<25$ years $($ adj.OR $=2.03,95 \% \mathrm{CI}=1.70$ $2.44), 25$ to 29 years $(\operatorname{adj} . \mathrm{OR}=1.85,95 \% \mathrm{CI}=1.52-2.26)$, and 30 to 34 years $($ adj. $\mathrm{OR}=1.34,95 \% \mathrm{CI}=1.04-1.74)$; worked as manual workers (adj.OR=2.49, $95 \% \mathrm{CI}=1.94$ 3.22), agricultural sector's self-employed (adj.OR $=1.91$, $95 \% \mathrm{CI}=1.60-2.28$ ), professional and other jobs (adj. $\mathrm{OR}=1.79,95 \% \mathrm{CI}=1.46-2.19$ (Table1).

Table 1: Multivariable analysis of modern contraceptive use and other factors among women in Cambodia

\begin{tabular}{|l|c|c|c|c|c|c|}
\hline Variable & Number & \% MC & Cru.OR & Adj.OR & $\mathbf{9 5 \% C I}$ & P-value \\
\hline Women's age & & & & & & $<\mathbf{0 . 0 0 1}$ \\
\hline$\geq 35$ & 2941 & 42.23 & 1 & 1 & & \\
\hline $30-34$ & 1340 & 49.94 & 1.36 & 1.34 & $1.04-1.74$ & \\
\hline $25-29$ & 1551 & 58.11 & 1.90 & 1.85 & $1.52-2.26$ & \\
\hline$<25$ & 1774 & 60.28 & 2.08 & 2.03 & $1.70-2.44$ & \\
\hline Women's occupation & & & & & & $<\mathbf{0 . 0 0 1}$ \\
\hline Unemployed & 1503 & 40.30 & 1 & 1 & & \\
\hline Professional and other jobs & 1712 & 51.91 & 1.60 & 1.79 & $1.46-2.19$ & \\
\hline Agricultural-Self employed & 3223 & 52.36 & 1.63 & 1.91 & $1.60-2.28$ & \\
\hline Manual & 1168 & 59.91 & 2.21 & 2.49 & $1.94-3.22$ & \\
\hline Geographical region & & & & & & $<\mathbf{0 . 0 0 1}$ \\
\hline Central plain and Plateau & 4492 & 48.93 & 1 & 1 & & \\
\hline Tonle sap and Coastal sea & 3114 & 54.07 & 1.23 & 1.34 & $1.15-1.56$ & \\
\hline
\end{tabular}




\begin{tabular}{|c|c|c|c|c|c|c|}
\hline Variable & Number & $\% \mathrm{MC}$ & Cru.OR & Adj.OR & $95 \%$ CI & P-value \\
\hline Age at first marriage & & & & & & $<0.001$ \\
\hline$\geq 21$ & 2531 & 45.25 & 1 & 1 & & \\
\hline $18-20$ & 2615 & 53.84 & 1.41 & 1.38 & $1.18-1.62$ & \\
\hline$<18$ & 2460 & 54.01 & 1.42 & 1.57 & $1.33-1.86$ & \\
\hline Number of living children & & & & & & $<0.001$ \\
\hline 0,1 & 2165 & 42.55 & 1 & 1 & & \\
\hline 2 & 2322 & 59.02 & 1.94 & 2.22 & $1.82-2.70$ & \\
\hline$\geq 3$ & 3118 & 50.98 & 1.40 & 2.55 & $1.96-3.31$ & \\
\hline Number of induced abortions & & & & & & 0.023 \\
\hline None & 6324 & 50.16 & 1 & 1 & & \\
\hline$\geq 1$ & 1282 & 55.37 & 1.23 & 1.24 & $1.03-1.49$ & \\
\hline $\begin{array}{l}\text { Marriage to first birth interval } \\
\text { (months) }\end{array}$ & & & & & & $<0.001$ \\
\hline$\geq 25$ & 2067 & 44.80 & 1 & 1 & & \\
\hline $12-24$ & 3590 & 52.26 & 1.35 & 1.39 & $1.20-1.60$ & \\
\hline$<12$ & 1949 & 55.39 & 1.53 & 1.64 & $1.37-1.96$ & \\
\hline \multicolumn{6}{|c|}{ Received FP information from community councils } & 0.007 \\
\hline No & 5664 & 49.62 & 1 & 1 & & \\
\hline Yes & 1942 & 55.15 & 1.25 & 1.24 & $1.06-1.45$ & \\
\hline \multicolumn{6}{|c|}{ Visited health facility during the last 12 months } & 0.001 \\
\hline Yes & 3889 & 50.33 & 1 & 1 & & \\
\hline No & 3717 & 51.78 & 1.06 & 1.23 & $1.09-1.38$ & \\
\hline \multicolumn{6}{|c|}{$\begin{array}{l}\text { Perceived problems in accessing health services (distance to health facilities, affordability, permission to go, } \\
\text { and presence of companion) }\end{array}$} & 0.008 \\
\hline$\geq 1$ barrier & 5724 & 49.50 & 1 & 1 & & \\
\hline No barrier & 1882 & 55.69 & 1.28 & 1.23 & $1.05-1.43$ & \\
\hline Fertility preference & & & & & & $<0.001$ \\
\hline Want within 2 years & 813 & 23.07 & 1 & 1 & & \\
\hline Want after 2 years & 2162 & 59.65 & 4.93 & 5.35 & $4.09-7.00$ & \\
\hline Want, unsure timing & 139 & 55.32 & 4.13 & 4.40 & $2.75-7.04$ & \\
\hline Undecided/want no more & 4492 & 51.81 & 3.59 & 2.97 & $2.32-3.82$ & \\
\hline Husband's desire for children & & & & & & 0.002 \\
\hline Do not know & 937 & 41.00 & 1 & 1 & & \\
\hline Both want same & 4876 & 52.30 & 1.58 & 1.45 & $1.18-1.79$ & \\
\hline Husband wants more & 1340 & 52.28 & 1.57 & 1.49 & $1.18-1.88$ & \\
\hline Husband wants fewer & 453 & 54.52 & 1.72 & 1.71 & $1.23-2.38$ & \\
\hline Ideal number of children & & & & & & $<0.001$ \\
\hline$\geq 5$ & 1056 & 38.18 & 1 & 1 & & \\
\hline 4 & 2029 & 47.95 & 1.50 & 1.48 & $1.19-1.83$ & \\
\hline 3 & 2186 & 53.86 & 1.89 & 1.91 & $1.55-2.35$ & \\
\hline $0,1,2$ & 2335 & 56.88 & 2.14 & 2.65 & $2.09-3.37$ & \\
\hline
\end{tabular}




\section{Discussion}

Our study identified the factors associated with the use of modern contraceptives among women of reproductive age in Cambodia. The result showed that about half (51.04\%) of respondents used modern contraceptive method. It was in line with the uptake rate in a study conducted in Rwanda (50.40\%). ${ }^{16}$ However,this finding was lower than a study in Kenya $(58.8 \%) .{ }^{17}$ Thepossible discrepancy might be because our study covered both urban and rural areas. Women residing in rural areas of Cambodia have limited access to modern contraceptives from socioeconomic condition as well as health service system.

A significant relationship between women's age and modern contraceptive use was observed in this study. The use of modern contraception decreased with increasing age of the respondents. This might be due to the fact that women often think they may be too young or immature to take good care of a child and may have to drop or suspend their education; therefore, they used contraceptivesto avertpregnancy. This finding is in line with a study in Spain. ${ }^{18}$ It is commonly known that late adults in their menopausal phase tend to usecontraceptives less due to decreasedsexual activities and fertility. A study showed that age was negatively associated with contraceptive utilization. ${ }^{19}$

Women with less stable and paid job were more likely to use contraceptives. The economic constraints might force women to use contraceptives for fear of child rearing burden. Women who had two or more living children were much more likely to use modern contraceptives than those with one or no child. It was consistent with a studyin Ethiopia ${ }^{12}$,revealedthat as the use of modern contraceptives raised, the number of living children also raised. Generally, this might be influenced by the fact that women with more living children could satisfy their family size and minimize a substantial financial burden in their daily life.

A study in $\mathrm{Uganda}^{13}$ reported that women desired to have children after two years were more likely to utilize modern contraceptives than those desired children within two years. The main reasons for this delayed childbearing were that women could have more involvement on the labor market including higher education and career engagement.

The finding indicated that women whose husband desired few children were more likely to use modern contraceptives compared to those who did not know whether their husband preferred more, less or the same children. One of the possible explanations was men have been considered as the head of the family and responsible for all expensesand making a final decision in the family in Cambodian context. This study, in agreement with other findings, elucidates that a husband's desire for fewer children was found to be significantly correlated with contraceptive use. ${ }^{20,21}$ This study also found a significant relationship between the ideal number of children and modern contraception. When the ideal number of children decreased, the odds of women's use of modern contraceptives increased. This is probably a reflection of the fact that women may not reach their desired family size or prefer to discuss with their spouse after having one child. However, women are more likely to use contraceptivesto preventpregnancy. This result is in line with other studies in Ethiopia and Zimbabwe. ${ }^{21,22}$ Sources of family planning information and accessibilities to health services also increased the odds of contraceptive uses. This might reflect the better coverage of services and access to modern contraceptives in the areas.

Limitation: The major strength of the study is this survey covered all areas of Cambodia with a large sample size. However, as a cross-sectional study, a causal relationship between modern contraceptive use and other explanatory variables could not be established. Future study should be a longitudinal study with the aim of identifying relevant trends and patterns of contraception over a long time period.

\section{Conclusion}

About half of women used modern method in Cambodia. Factors strongly associated with modern contraceptive utilization were number of living children, fertility preferences, husband's desire for children, and number of ideal children as well as sociodemographic, health services and health information. Recommendations are to raise awareness of family planning services to both genders. Policy makers, communities, and partitioners should establish multi-sectoral collaboration for integrated family planning programsto improve the access to health education and family planning services. Promoting income-generating activities and creating more employment opportunities are essential for vulnerable families that faced inaccessible to health services and other essential resources. 
Ethical Considerations:Thisstudywas approved by the KhonKaen University Ethics Committee for Human Research based on the Declaration of Helsinki and the ICH Good Clinical Practice Guidelines (reference number (HE632199).

Acknowledgement: The authors would like to express our sincere appreciation to the CDHS for the data and the Faculty of Public Health, KhonKaen University, Thailand for funding.

Conflict of Interest: No conflicts of interestto declare.

Source of Funding: Faculty of Public Health, KhonKaen University

\section{References}

1. Endriyas M, Eshete A, Mekonnen E, Misganaw T, Shiferaw M, Ayele S. Contraceptive utilization and associated factors among women of reproductive age group in Southern Nations Nationalities and Peoples' Region, Ethiopia: cross-sectional survey, mixed-method. Contracept Reprod Med. 2017;2.

2. United Nations, Department of Economic and Social Affairs, Population Division. World Family Planning 2017 - Highlights (ST/ESA/SER.A/414). 2017.

3. Bongaarts J, Cleland J, Townsend J. Family Planning Programs for the 21st Century: Rationale and Design. New York: Population Council. 2012.

4. United Nations, Department of Economic and Social Affairs, Population Division. Contraceptive Use by Method 2019: Data Booklet. UN; 2019.

5. Sedgh G, Singh S, Hussain R. Intended and Unintended Pregnancies Worldwide in 2012 and Recent Trends. Stud Fam Plann. 2014;45(3):30114.

6. Alemayehu GA, Fekadu A, Yitayal M, Kebede Y, Abebe SM, Ayele TA, et al. Prevalence and determinants of contraceptive utilization among married women at Dabat Health and Demographic Surveillance System site, northwest Ethiopia. Bmc Womens Health. 2018;18:118.

7. Achana FS, Bawah AA, Jackson EF, Welaga P, Awine T, Asuo-Mante E, et al. Spatial and sociodemographic determinants of contraceptive use in the Upper East region of Ghana. Reprod Health. 2015;12.
8. Gilliam ML, Neustadt A, Whitaker A, Kozloski M. Familial, Cultural and Psychosocial Influences of Use of Effective Method of Contraception among Mexican-American Adolescents and Young Adults. J Pediatr Adolesc Gynecol. 2011;24(2):79-84.

9. Cohen B. Family Planning Programs, Socioeconomic Characteristics, and Contraceptive Use in Malawi. World Dev. 2000;28(5):843-60.

10. Ekani-Bessala M-M, Carre N, Calvez T, Thonneau P. Prevalence and determinants of current contraceptive method use in a palm oil company in Cameroon. Contraception. 1998;58(1):29-34.

11. Habyarimana F, Ramroop S. Spatial Analysis of Socio-Economic and Demographic Factors Associated with Contraceptive Use among Women of Childbearing Age in Rwanda. Int J Environ Res Public Health. 2018;15(11).

12. Mohammed A, Woldeyohannes D, Feleke A, Megabiaw B. Determinants of modern contraceptive utilization among married women of reproductive age group in North Shoa Zone, Amhara Region, Ethiopia. Reprod Health. 2014 Feb 3;11(1):13.

13. Asiimwe JB, Ndugga P, Mushomi J, Manyenye Ntozi JP. Factors associated with modern contraceptive use among young and older women in Uganda; a comparative analysis. BMC Public Health. 2014 Sep 8;14(1):926.

14. Bajracharya A, Veasnakiry L, Rathavy $\mathrm{T}$, Bellows B. Increasing Uptake of Long-Acting Reversible Contraceptives in Cambodia Through a Voucher Program: Evidence From a Differencein-Differences Analysis. Glob Health Sci Pract. 2016;4(Suppl 2):S109-21.

15. Sok K, Chhay S, They K. Cambodia Demographic and Health Survey 2014. Phnom Penh, Cambodia, and Rockville, Maryland, USA: National Institute of Statistics, Directorate General for Health, and ICF International 2015. 2014.

16. Brunie A, Tolley EE, Ngabo F, Wesson J, Chen M. Getting to $70 \%$ : Barriers to modern contraceptive use for women in Rwanda. Int J Gynecol Obstet. 2013;123(S1):e11-5.

17. Ochako R, Mbondo M, Aloo S, Kaimenyi S, Thompson R, Temmerman M, et al. Barriers to modern contraceptive method uptake among young women in Kenya: a qualitative study. BMC Public Health. 2015 Feb 10;15(1):118.

18. Ruiz-Muñoz D, Pérez G, Gotsens M, Rodríguez- 
Sanz M. Regional inequalities in the use of contraception in Spain: A multilevel approach. Health Place. 2012;18(2):408-14.

19. Alemayehu GA, Fekadu A, Yitayal M, Kebede Y, Abebe SM, Ayele TA, et al. Prevalence and determinants of contraceptive utilization among married women at Dabat Health and Demographic Surveillance System site, northwest Ethiopia. BMC Womens Health. 2018 Jul 3;18(1):118.

20. Lasong J, Zhang Y, Gebremedhin SA, Opoku S, Abaidoo CS, Mkandawire T, et al. Determinants of modern contraceptive use among married women of reproductive age: a cross-sectional study in rural Zambia. BMJ Open. 2020 Mar 1;10(3):e030980.

21. Tiruneh FN, Chuang KY, Ntenda PAM, Chuang YC. Factors associated with contraceptive use and intention to use contraceptives among married women in Ethiopia. Women Health. 2016 Jan 2;56(1):1-22.

22. Hindin MJ. Women's Autonomy, Women's Status and Fertility-Related Behavior in Zimbabwe. Popul Res Policy Rev. 2000;19(3):255-82. 